\title{
Features technologies calculation of constructions with concrete-filled steel tubes
}

\author{
Ksenia Bolotova ${ }^{1}$, Sergey Lukichev ${ }^{1, *}$, Vera Murgul $^{1}$ \\ ${ }^{1}$ Peter the Great Saint-Petersburg Polytechnic University, 195251 St. Petersburg, Russia
}

\begin{abstract}
In modern construction industry around the world constructions with concrete-filled steel elements are used more and more frequently. Usage of such structures allows substantially reduce the weight and cost of construction works (about 3 times) comparing with similar structures made of reinforced concrete. Labor costs are reduced in 5 times. Comparing with metal structures cost reduces significantly (up to 40\%). Also the consumption of steel with a slight weight gain reduces in 3 times. In our country currently usage of concrete-filled steel structures is not widely used due to the lack of studies of such structures under different influences. Now there is no the normative base offering a calculation methodology of concrete-filled steel tubes, taking into account the modulus of elasticity in bending metal and concrete because at some point collaboration of materials is lost. This article presents the main trends in the usage of concrete-filled steel tubes in the construction. The advantages and disadvantages of such constructions are given, main constructive solutions are shown. The basic technologies of calculation of buildings with concrete-filled steel tubes are reviewed and analyzed.
\end{abstract}

\section{Introduction}

A good example of when concrete and steel are mutually help resist the force effect, which leads to an increase in the bearing capacity of the element, are the pillars of steel tubes filled with concrete. Working pipe-concrete rod elements has a number of significant features, compared with conventional reinforced concrete elements, reinforced rod fitting and also compared to the rigid concrete elements with an open structure reinforcement arranged inside the concrete section [1].

Features the work of compressed and compressed-bent concrete-filled steel elements are described in a number of works. In many ways, these descriptions are the same.

The main features of the concrete-filled steel tubes:

- High load-bearing capacity;

- Steel ferrule performs the role of longitudinal and transverse reinforcement;

- High reliability while using high-strength concrete kernel;

- High resistance of a building to seismic influences;

- Increased fire resistance of bearing elements comparing to steel frame structures;

* Corresponding author: serj_lu@mail.ru 
- High durability and weather resistance of concrete;

- Lower frame weight [2]

Ultimately, all of this leads to a reduction in the consumption of material and money resources to manufacture concrete-filled steel elements. Concrete-filled steel are using effectively as highly stressed structural members and provide high security of buildings. Widespread using of concrete-filled steel tubes in our country is constrained by lack of domestic rules on their design and calculation. There is still no reliable calculation model for practical use of concrete-filled steel section in limit state, reflecting its specific characteristics. In view of this, it may be assumed that further researches in this area are promising. The idea of using metal pipes filled with concrete for manufacture of loadbearing columns of buildings was proposed by engineer John Lally. At present, concretefilled metal pipes used as columns of the high-rise buildings or fencings of pits. It may appear that the concrete-filled steel constructions have no weaknesses. However, it's falce. For example, these constructions are very difficult to work together the metallic tubular casing and beton core at all stages of the operation. Tube starts working as ferrule with loads under which starts cracking [3-5].

\section{Material and methods}

Metal pipe in concrete-filled steel structures simultaneously performs the role of shell and the longitudinal and transverse reinforcement. It is able to perceive emerging efforts from different angles and in all directions. Concrete in tube-shell, being under the Triaxial compression withstands stress well above cube-strength and prism strength. Pipe prevents the formation of microcracks in concrete core, due to fullness of concrete probability of local buckling of pipes' walls and a total loss of stability in general is significantly reduced[6-7].

The existing standards and researches offer different methods for calculating steel shells, filled with concrete, off-center and axial compression. Widely known dependence for evaluation of bearing capacity of concrete-filled steel central compressed columns of circular cross-section:

$$
N=c R_{b} A_{b}+\alpha R_{c} A_{c}
$$

where $\mathrm{c}$ - the coefficient of the joint work of concrete and steel; $\alpha$ - the coefficient of hardening; $R_{b}, A_{b}$ - tensile strength and cross-sectional area of concrete, respectively; $R_{c}, A_{c}$ -yield point steel and cross-sectional area of the pipe, respectively.

Formula (1) does not fully reflect the physical essence of the bearing capacity of the concrete-filled steel tube, because the concrete compressed shell core is hardened, not the steel shell. Compression level depends on the ratio of the shell wall thickness and diameter of the concrete core. Most appeared later dependencies can be presented in the summarized form:

$$
N=\left(c R_{b}+d\right) A_{b}+\alpha R_{\mathrm{c}} A_{\mathrm{c}}
$$

where $\mathrm{c}, \mathrm{d}, \alpha$ - coefficients.

Conditions for limit state:

- Achieving normal strains of the axial direction in the concrete core values of concrete strength under tri-axial compression $\sigma_{\mathrm{bz}}=\mathrm{R}_{\mathrm{b} 3}$;

- Achievement of the stress intensity in the most compressed fiber steel shell physical or adverse yield strength $\sigma_{\mathrm{pi}}=\sigma_{\mathrm{p}, \mathrm{y}}$;

- Achieving the axial direction by normal strains in most stretched fiber steel shell yield $\sigma_{\mathrm{pz}}=\sigma_{\mathrm{p}, \mathrm{y}}$. 
Considering the internal static undetectable concrete-filled steel construction the first condition of occurrence of limit State should be performed in conjunction with the second or third (fig.1)
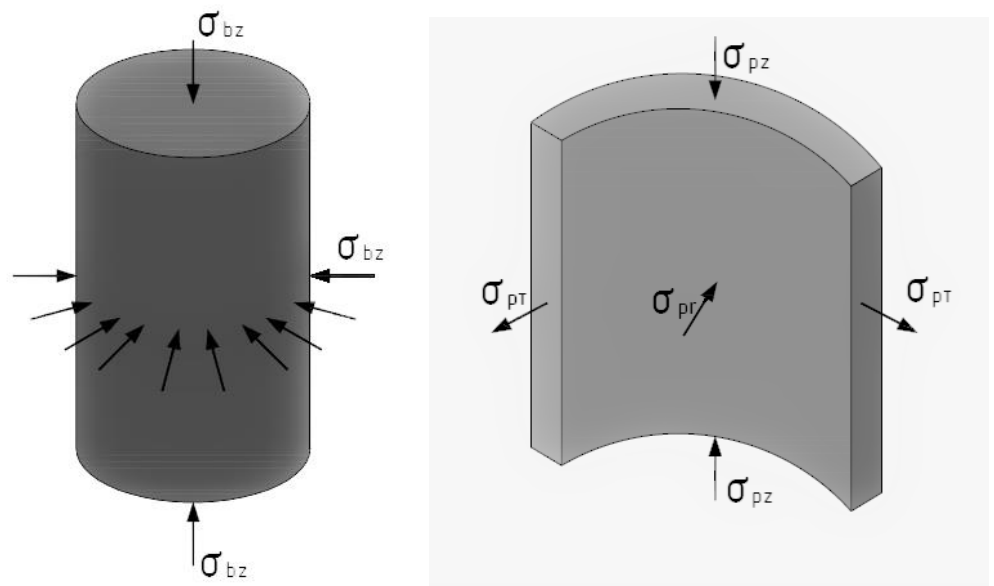

Figure. 1. Stress state of the concrete core and a steel shell in axial compression of concrete-filled steel tubes.

To ensure the serviceability of the columns under the action at design loads of magnitude of steel shell deformations should be limited to appropriate values [8-12].

In this regard, the strength calculation of normal sectional concrete-filled steel tubes in the general case of eccentrical compression should be made on the basis of nonlinear deformation of reinforced concrete model taking into account the peculiarities of deformation of the concrete core and a steel shell in terms of volumetric stress state. Deformation ability of materials and changing the coefficients of shear deformations in the concrete core and a steel shell stress level increases should also be considered for a more accurate calculation [13-15].

A common system for calculating the ratio of normal physical sections of concretefilled steel tubes on strength, as in conventional deformation models take from the joint review:

- equations of equilibrium of external forces and inner forces in the normal section of element;

- $\quad$ equations, establishing the distribution of axial deformation of concrete and reinforcement for normal cross section, on the basis of a flat turn and flat bias section;

- dependencies linking stress and relative longitudinal deformation of concrete, steel cages and longitudinal reinforcement.

\section{Results and Discussion}

Consider the existing method for calculating pipe-concrete structures with metal shell. Consider the example of column height has a constant cross section and a steel tube of C235 steel with an outer diameter of $490 \mathrm{~mm}$ and a wall thickness of $8 \mathrm{~mm}$, class B25 filled with concrete. The estimated height of the column is $3 \mathrm{~m}$.

Column has the following loads:

- the longitudinal compressive force $\mathrm{N}=4168 \mathrm{kN}$;

- bending moments $\mathrm{M}_{\mathrm{y}}=16.6 \mathrm{kNm}, \mathrm{M}_{\mathrm{z}}=51 \mathrm{kNm}$;

- $\quad$ shear force $\mathrm{Q}_{\mathrm{y}}=24 \mathrm{kN}$. 
Let's calculate concrete-filled steel constructions using different approaches:

1) Reduction of concrete filled tube section to the steel

Under this approach, the composite cross section of pipe-concrete column is one material - steel, taking into consideration that in addition to the longitudinal force acting on the column and bending moments, so the column is calculated as the eccentric compression. And the calculation is carried out in two variants - considering only the elastic properties and taking into account the plastic deformation. And the calculation is performed in two version: with only elastic properties and considering plastic deformation.

a) While calculating the elastic stage area steel square is accepted $A_{s}=117.8 \mathrm{~cm}^{2}$, square concrete $A_{b}=1865 \mathrm{~cm}^{2}$. The calculated resistance steel $R_{s}=235 \mathrm{MPa}$ concrete $R_{b}=14.8$ $\mathrm{MPa}$. Reduction coefficient $\mathrm{n}=\mathrm{Eb} / \mathrm{Es}=0.13$.

The calculation is made according to the formula

$$
\frac{N}{A_{n}} \pm \frac{M_{y}}{I_{n}} \leq R_{n} \gamma
$$

With that in the margin of safety was thought that during the eccentrical compression the bending moment is perceived only a steel pipe. Working stresses were equal $142,5 \mathrm{MPa}$ that substantially less of the calculated resistance $\mathrm{R}_{\mathrm{s}}=235 \mathrm{MPa}$. Factor of safety $\mathrm{k}=$ $235 / 142.5=1.65$.

b) In the calculation taking into account the plastic deformation of concrete was taken into account the concrete elastic modulus decrease administration coefficients $\beta=0.45$ and consequently reduction coefficient $\mathrm{n}=\beta \mathrm{E}_{\mathrm{b}} / \mathrm{E}_{\mathrm{s}}=0,06$. Operating voltage were equal to $201.9 \mathrm{MPa}$, which is also less than the calculated resistance of $\mathrm{R}_{\mathrm{s}}=235 \mathrm{MPa}$. Factor of strength with respect to $\mathrm{k}=235 / 201.9=1.16$.

2) The calculation of a concrete structure with a rigid reinforcement

In this case, the marginal bearing capacity of pipe-concrete column section, which was found to be $\mathrm{N}_{\mathrm{pr}}=5877 \mathrm{kN}$, which is higher than the force of $\mathrm{N}=4168 \mathrm{kN}$, the margin of safety is $\mathrm{k}=5877 / 4168=1.41$.

3) The project jodnogo normative document, load-bearing capacity of the compressed pipe-concrete column is given by:

$$
\mathrm{N} \leq \mathrm{N}_{\text {per }}=\varphi_{\gamma \mathrm{bs}}\left(\mathrm{R}_{\mathrm{b}} \mathrm{A}_{\mathrm{b}}+\gamma_{\mathrm{s} 2} \mathrm{R}_{\mathrm{s}} \mathrm{A}_{\mathrm{s}}\right)
$$

Here $\varphi$ - buckling coefficient, $\mathrm{R}_{\mathrm{b}}$-concrete design resistance in the pipe-concrete:

$\mathrm{R}_{\mathrm{b}}=0,65 \mathrm{~B}\left(1+\mu_{\mathrm{pb}} \mathrm{a}\right)$

where $\mathrm{a}=0,35$; The class of concrete strength, $\mu \mathrm{pb}$ - reinforcement ratio, and $\mu_{\mathrm{pb}}=$ $117.8 / 1865=0.063$. In this case, $\mathrm{Rb}=19.9 \mathrm{MPa}$.

The result is a $\mathrm{N}_{\text {per }}=5543.4 \mathrm{kN}$, ie the margin of safety is $\mathrm{k}=5543.4 / 4168=1.33$.

4) Verification methodology using Eurocode 4

a) Calculation of pipe-concrete column axial compression according to international regulations Eurocode 4 gives the following meaning bearing capacity column $\mathrm{N}_{\text {osszh }}=$ $5476.72 \mathrm{kN}$, ie margin of $\mathrm{k}=5476.72 / 4168=1.29$.

b) Calculation of pipe-concrete columns on the eccentric contraction accordance with international regulations Eurocode 4 gives the following meaning bearing pillar ability Nvnetsszh $=5335 \mathrm{kN}$, ie the margin of safety is $\mathrm{k}=5335 / 4168=1.28$.

We reduce the results in Table 1. 
Table 1. Comparison of methodologies.

\begin{tabular}{|c|c|c|c|c|c|c|}
\hline Methods & 1a & $\mathbf{1 0}$ & $\mathbf{2}$ & $\mathbf{3}$ & 4a & 40 \\
\hline $\begin{array}{c}\text { The bearing } \\
\text { capacity of } \\
\text { pipe-concrete } \\
\text { columns, } \mathrm{kN}\end{array}$ & - & - & 5877 & 5543.4 & 5476.72 & 5335 \\
\hline $\begin{array}{c}\text { Factor of safety } \\
\mathrm{k}\end{array}$ & 1.65 & 1.16 & 1.41 & 1.33 & 1.29 & 1.28 \\
\hline
\end{tabular}

\section{Conclusion}

Concrete-filled steel is a concrete enclosed in a metal pipe of round or a more complex cross-section. Concrete in such column is under triaxial compression and because the bearing capacity and deformability of concrete-filled steel in compression is highly increasing. Comparing the concrete-filled steel tubes with metal column with the same bearing capacity and weight reduction of metal consumption in case of concrete-filled steel can achieve the $50 \%$. If reinforced concrete columns with the same amount of metal as a tubular sheath, it appears that the pipe-concrete section of the column at the same load bearing capacity can also be reduced by up to $50 \%$.

Now filled with concrete constructions can be made not only on the basis of circular tubular membranes. It is possible to use polygonal tubular membranes of cold forming with different numbers of faces that are already used in some constructions. This promising modification of concrete-filled steel constructions allows to expand range of design solutions of steel-concrete composite construction that enhances their aesthetic qualities.

Comparative analysis of 4 calculation methods of strength shows that the calculation of concrete-filled steel tubes by using the second, third and fourth methodologies give similar results, while the calculation using the transformed section gives a significantly different results, moreover record of plastic deformations leads not to increasing but to reduction of safety factor in strength.

\section{References}

1. A. L. Krishan, A. I. Sagadatov, I. V. Atkishkin, UGTU-UPI, 108-110 (2004)

2. A. L. Krishan, AOPICUD, 725-733 (2005)

3. G. V. Nesvetaev, I. V. Rezvan, FR 12, 580-583 (2011)

4. V. P. Mitrofanov, N. Dergam, PoltNTU, 91 (2008)

5. A. L. Krishan, V. V. Remnev, ICE 10, 22-24 (2009)

6. I. M. Garanzha, MC 20, 45-53 (2014)

7. I. A. Duvanova, I. D. Sal'manov, CUBS 21, 89-103 (2014)

8. L. I. Storozhenko, A. V. Semko, UC 63, 59-67 (2005)

9. I.I. Ovchinnikov, I.G. Ovchinnikov, G.V. Chesnokov, E.S. Mikhaldykin, IJN, 1-20 (2015)

10. J. Seo, H. Park, ASCE, 716-726 (2015)

11. U.K. Zolkafli, Z. Yahya, N. Zakaria, F.W. Akashah, A.S. Ali, SS 33, 309-321 (2015)

12. C.R. Liñán, M.J. Morales Conde, P.R. De Hita, F.P. Gálvez, IJAH 9, 324-340 (2015)

13. B. Carlo, C. Pietro, D. Vincenzo, F. Nora, IAARC, 1-8 (2015)

14. I. Stefanou, M. Fragiadakis, I.N. Psycharis, CMAS 37, 61-82 (2015)

15. SP 63.13330.2012, Concrete and won concrete construction. Design requirements, (2013) 